\title{
Nonlinear boundary value conditions and ordinary differential systems with impulsive effects
}

\section{Tingting $\mathrm{Hu}^{*}$}

\section{"Correspondence: tingtinghu0902@163.com Department of Mathematics, Nanjing Normal University, Nanjing 210097, P.R. China}

\begin{abstract}
We investigate solutions to nonlinear operator equations which are difficult to investigate with variational methods and obtain some abstract existence results by topology degree methods. These results apply to ordinary differential systems with impulsive effects satisfying nonlinear boundary value conditions, and we obtain some new results.
\end{abstract}

Keywords: nonlinear boundary value conditions; ordinary differential systems with impulsive effects; topology degree methods; operator equations; index theory

\section{Introduction}

We are interested in the problem

$$
\begin{aligned}
& \ddot{x}+V^{\prime}(t, x)=0, \\
& x(0)=M_{0}\left(x(0), x^{\prime}(0), x(1), x^{\prime}(1)\right), \\
& x(1)=M_{1}\left(x(0), x^{\prime}(0), x(1), x^{\prime}(1)\right),
\end{aligned}
$$

where $V \in C^{1}\left([0,1] \times \mathbf{R}^{n}, \mathbf{R}\right), V^{\prime}$ denotes the gradient of $V$ with respect to $x$ and $M_{0}, M_{1}$ : $\mathbf{R}^{4 n} \rightarrow \mathbf{R}^{n}$. When $M_{0} \equiv x_{0}, M_{1} \equiv x_{1}$ are constants, Ekeland et al. [1] investigated the problem in 1996. Setting $x=y+(1-t) x_{0}+t x_{1}$, then (1.1)-(1.3) is equivalent to the problem

$$
\begin{aligned}
& \ddot{y}+V^{\prime}\left(t, y+(1-t) x_{0}+t x_{1}\right)=0, \\
& y(0)=0=y(1),
\end{aligned}
$$

and its solutions are the critical points of the functional

$$
I(y) \equiv \frac{1}{2} \int_{0}^{1}\left[|\dot{y}(t)|^{2}-V\left(t, y+(1-t) x_{0}+t x_{1}\right)\right] d t
$$

defined on some suitable function space. However, if one of $M_{0}$ and $M_{1}$ is not constant, (1.1)-(1.3) cannot be solved by variational methods generally. Note that the problem is

\section{Springer}


equivalent to the integral equation

$$
x(t)=\int_{0}^{1} G(t, s) V^{\prime}(s, x(s)) d s+\left(M_{1}-M_{0}\right) t+M_{0},
$$

where $G(t, s)=t(1-s)$ as $0 \leq t \leq s \leq 1$ and $G(t, s)=s(1-t)$ as $0 \leq s \leq t \leq 1, M_{i}=$ $M_{i}\left(x(0), x(1), x^{\prime}(0), x^{\prime}(1)\right)(i=0,1)$.

Let $X=L^{2}\left([0,1], \mathbf{R}^{n}\right), D(A)=H_{0}^{2}\left([0,1], \mathbf{R}^{n}\right)=\left\{x \in H^{2}\left([0,1], \mathbf{R}^{n}\right) \mid x(0)=0=x(1)\right\}$, $A: D(A) \rightarrow L^{2}\left([0,1], \mathbf{R}^{n}\right)$ by $(A x)(t)=-\ddot{x}(t), N: C^{1}\left([0,1], \mathbf{R}^{n}\right) \rightarrow L^{2}\left([0,1], \mathbf{R}^{n}\right)$ by $(N x)(t)=V^{\prime}(t, x(t)), Y=C^{1}\left([0,1], \mathbf{R}^{n}\right), M: C^{1}\left([0,1], \mathbf{R}^{n}\right) \rightarrow C^{1}\left([0,1], \mathbf{R}^{n}\right)$ by $(M x)(t)=$ $(1-t) M_{0}\left(x(0), x^{\prime}(0), x(1), x^{\prime}(1)\right)+t M_{1}\left(x(0), x^{\prime}(0), x(1), x^{\prime}(1)\right)$. Then $A$ is an unbounded selfadjoint invertible operator in $X$ with $\sigma(A)=\left\{k^{2} \pi^{2}\right\}_{i=1}^{\infty}=\sigma_{d}(A)$, and (1.1)-(1.3) turn to the following operator equation:

$$
x=A^{-1} N(x)+M(x) .
$$

In this paper we also denote $N(x)$ and $M(x)$ by $N x$ and $M x$, respectively, when there is no confusion. We will first investigate (1.5), and then as applications we investigate ordinary differential systems satisfying nonlinear boundary value conditions including (1.1)-(1.3). In particular, we will investigate differential systems with impulsive effects.

Let $X$ be a real infinite-dimensional separable Hilbert space with norm $\|\cdot\|$ and inner product $(\cdot, \cdot)$. Let $A: D(A) \subset X \rightarrow X$ be an unbounded self-adjoint and invertible operator satisfying $\sigma(A)=\sigma_{d}(A)$. Assume that $Y$ is a Banach space with the norm $\|\cdot\|_{Y}$ satisfying $D(A) \subset Y \subset X$, the inclusion map from $D(A)$ to $Y$ is compact and the inclusion from $Y$ to $X$ is continuous. Assume $N: Y \rightarrow X$ is continuous, $M: Y \rightarrow Y$ is compact and satisfies $\|M(x)\|_{Y} \leq \rho$ for all $x \in Y$ and some $\rho>0$.

We will also use the following assumptions:

$\left(\mathrm{N}_{1}\right)$ There exists $B: Y \rightarrow \mathcal{L}_{s}(X), B_{1}, B_{2} \in \mathcal{L}_{s}(X)$ with $i_{A}\left(B_{1}\right)=i_{A}\left(B_{2}\right), v_{A}\left(B_{2}\right)=0$ and there is an $\varepsilon>0$ such that $B_{1} \leq B(x) \leq B_{2}, B_{1} \geq \varepsilon I d$ and $N x=B(x) x+C(x),\|C(x)\| \leq \rho$ for all $x \in Y$ and some $\rho>0$.

$\left(\mathrm{N}_{2}\right)$ There exists $B_{0}: Y \rightarrow \mathcal{L}_{s}(X), B_{01}, B_{02} \in \mathcal{L}_{s}(X)$ with $i_{A}\left(B_{01}\right)=i_{A}\left(B_{02}\right), v_{A}\left(B_{02}\right)=0$ and there is an $\epsilon>0$ and some $r>0$ such that $B_{01} \geq \varepsilon I d, B_{01} \leq B_{0}(x) \leq B_{02}$ and $N x=$ $B_{0}(x) x$ for all $x \in Y$ with $\|x\|_{Y} \leq r$.

(M) $M(x)=o\left(\|x\|_{Y}\right)$ as $\|x\|_{Y} \rightarrow 0$.

Theorem 1.1 Assume $N$ satisfies $\left(\mathrm{N}_{1}\right)$. Then (1.5) has one solution. If further $\left(\mathrm{N}_{2}\right)$ and $(\mathrm{M})$ hold, then (1.5) has a nontrivial solution provided $i_{A}\left(B_{01}\right)-i_{A}\left(B_{1}\right)$ is odd.

We will give the proof in the next section, and now we return to a discussion of the problem at the beginning of the paper. Let $|\cdot|$ denote the usual norm in $\mathbf{R}^{m}$ for positive integer $m$. We need the following assumptions:

$\left(\mathrm{V}_{1}\right)$ There is a $\bar{B}:[0,1] \times \mathbf{R}^{n} \rightarrow \mathcal{L}_{s}\left(\mathbf{R}^{n}\right)$ with $\bar{B}(\cdot, x(\cdot)) \in L^{\infty}\left([0,1], \mathcal{L}_{s}\left(\mathbf{R}^{n}\right)\right)$ for all $x \in$ $C\left([0,1], \mathbf{R}^{n}\right)$ and there exists $\bar{B}_{1}, \bar{B}_{2} \in L^{\infty}\left([0,1], \mathcal{L}_{s}\left(\mathbf{R}^{n}\right)\right)$ such that

$$
V^{\prime}(t, x)=\bar{B}(t, x) x+h(t, x), \quad \bar{B}_{1}(t) \leq \bar{B}(t, x) \leq \bar{B}_{2}(t)
$$

for all $(t, x) \in[0,1] \times \mathbf{R}^{n}, h:[0,1] \times \mathbf{R}^{n} \rightarrow \mathbf{R}^{n}$ is bounded. 
$\left(\mathrm{V}_{2}\right)$ There exists $\bar{B}_{0}:[0,1] \times \mathbf{R}^{n} \rightarrow \mathcal{L}^{\infty}\left(\mathbf{R}^{n}\right)$ with $\bar{B}_{0}(\cdot, x(\cdot)) \in L^{\infty}\left([0,1], \mathcal{L}_{s}\left(\mathbf{R}^{n}\right)\right)$ for all $x \in$ $C\left([0,1], \mathbf{R}^{n}\right)$ and there exists $\bar{B}_{01}, \bar{B}_{02} \in L^{\infty}\left([0,1], \mathcal{L}_{s}\left(\mathbf{R}^{n}\right)\right)$ such that

$$
V^{\prime}(t, x)=\bar{B}_{0}(t, x) x, \quad \bar{B}_{01}(t) \leq \bar{B}_{0}(t, x) \leq \bar{B}_{02}(t)
$$

for all $(t, x) \in[0,1] \times \mathbf{R}^{n}$ with $|x| \leq r$ for some $r>0$.

$\left(\mathrm{M}_{1}\right) M_{i}(\xi)=o(|\xi|)$ as $|\xi| \rightarrow 0, M_{i}(i=0,1)$ are continuous and bounded.

We will also use the index $\left(v_{0, \pi}^{s}(\bar{B}), i_{0, \pi}^{s}(\bar{B})\right)$ concerning the following systems:

$$
\begin{aligned}
& \ddot{x}(t)+\bar{B}(t)=0, \\
& x(0)=0=x(1),
\end{aligned}
$$

where $\bar{B} \in L^{\infty}\left([0,1], \mathcal{L}_{s}\left(\mathbf{R}^{n}\right)\right)$.

Definition 1.1 (See Definition A.4) For any $\bar{B} \in L^{\infty}\left([0,1], \mathcal{L}_{s}\left(\mathbf{R}^{n}\right)\right)$, we define

$$
\begin{aligned}
& v_{0, \pi}^{s}(\bar{B})=\text { the dimension of the solution space of (1.6)-(1.7), } \\
& i_{0, \pi}^{s}(\bar{B})=\sum_{\lambda<0} v_{0, \pi}^{s}\left(\bar{B}+\lambda I_{n}\right) .
\end{aligned}
$$

Note that from Definition 1.1 for $c \in \mathbf{R}, \nu_{0, \pi}^{s}\left(c I_{n}\right)=0$ as $c \neq k^{2} \pi^{2}$ and $\nu_{0, \pi}^{s}\left(c I_{n}\right)=n$ as $c=k^{2} \pi^{2}$ for $k=1,2, \ldots$; and $i_{0, \pi}^{s}\left(c I_{n}\right)=0$ as $c \leq \pi^{2}$ and $i_{0, \pi}^{s}\left(c I_{n}\right)=k n$ as $k^{2} \pi^{2}<c \leq(k+1)^{2} \pi^{2}$ for $k=1,2, \ldots$.

Theorem 1.2 If V satisfies $\left(\mathrm{V}_{1}\right)$ with $i_{0, \pi}^{s}\left(\bar{B}_{1}\right)=i_{0, \pi}^{s}\left(\bar{B}_{2}\right), v_{0, \pi}^{s}\left(\bar{B}_{2}\right)=0$, then (1.1)-(1.3) has one solution. Furthermore, if $\left(\mathrm{V}_{2}\right)$ and $\left(\mathrm{M}_{1}\right)$ hold, then (1.1)-(1.3) has one nontrivial solution provided $i_{0, \pi}^{s}\left(\bar{B}_{01}\right)=i_{0, \pi}^{s}\left(\bar{B}_{02}\right), v_{0, \pi}^{s}\left(\bar{B}_{02}\right)=0$ and $i_{0, \pi}^{s}\left(\bar{B}_{01}\right)-i_{0, \pi}^{s}\left(\bar{B}_{1}\right)$ is odd.

Proof We only give the proof for the case that there exists $\epsilon>0$ such that $B_{1} \geq \epsilon I_{n}, B_{01} \geq$ $\epsilon I_{n}$. The complete proof will be given in Section 4 as a special case of a more general result. Let $X=L^{2}\left([0,1], \mathbf{R}^{n}\right), D(A)=\left\{x \in H^{2}\left([0,1], \mathbf{R}^{n}\right) \mid x(0)=0=x(1)\right\}$ and $Y=C^{1}\left([0,1], \mathbf{R}^{n}\right)$. The inclusion maps $D(A) \rightarrow Y, Y \rightarrow X$ are compact and continuous, respectively. Define $A: D(A) \rightarrow L^{2}\left([0,1], \mathbf{R}^{n}\right)$ by $(A x)(t)=-\ddot{x}(t)$, then $A$ is invertible. Define $N: Y \rightarrow X$ and $M: Y \rightarrow Y$ by $(N x)(t)=V^{\prime}(t, x(t))$ and $(M x)(t)=t M_{1}\left(x(0), x(1), x^{\prime}(0), x^{\prime}(1)\right)+(1-$ $t) M_{0}\left(x(0), x(1), x^{\prime}(0), x^{\prime}(1)\right)$, respectively. Then (1.1)-(1.3) is equivalent to (1.4) or (1.5). Because $M_{i}$ is bounded, there exists $c>0$ such that $\left|M_{i}(\xi)\right| \leq c$ for all $\xi \in \mathbf{R}^{4 n}, i=0,1$. Assume $\left\{x_{j}\right\} \subset Y$ is bounded. Then $\left\|M x_{j}\right\|_{Y} \leq 3 c$, and $\left|\left(M x_{j}\right)(t)-\left(M x_{j}\right)(s)\right| \leq 2 c|t-s|$, $\left|\left(M x_{j}\right)^{\prime}(t)-\left(M x_{j}\right)^{\prime}(s)\right|=0$ for all $t, s \in[0,1]$. By Ascoli-Arzela's theorem, $\left\{M x_{j}\right\}$ has a convergent subsequence in $Y$. Moreover, $M: Y \rightarrow Y$ is continuous via the continuity of $M_{i}$ $(i=0,1)$. So $M$ is compact. Because assumptions $\left(\mathrm{V}_{1}\right),\left(\mathrm{V}_{2}\right),\left(\mathrm{M}_{1}\right)$ imply $\left(\mathrm{N}_{1}\right),\left(\mathrm{N}_{2}\right),(\mathrm{M})$, Theorem 1.2 follows Theorem 1.1 directly.

\section{Remark}

1. As in [2], p.69, if we assume $V \in C^{2}\left([0,1] \times \mathbf{R}^{n}\right)$ and $\bar{B}_{1}(t) \leq V^{\prime \prime}(t, x) \leq \bar{B}_{2}(t)$ for all $(t, x) \in[0,1] \times \mathbf{R}^{n}$ with $|x| \geq r>0$, then $\left(\mathrm{V}_{1}\right)$ (with $\bar{B}_{1}, \bar{B}_{2}$ replaced by $\bar{B}_{1}-\epsilon I_{n}, \bar{B}_{2}+\epsilon I_{n}$ 
for small $\epsilon>0$ ) holds. In fact, for any $\epsilon>0$, there exists $\delta \in(0,1)$ such that

$$
\begin{aligned}
& \bar{B}_{1}-\frac{1}{2} \epsilon I_{n} \leq(1-\delta) \bar{B}_{1} \leq(1-\delta) \bar{B}_{2} \leq \bar{B}_{2}+\frac{1}{2} \epsilon I_{n}, \\
& \frac{1}{2} \epsilon I_{n} \leq \int_{0}^{\delta} V^{\prime \prime}(t, \theta x) d \theta \leq \frac{1}{2} \epsilon I_{n} .
\end{aligned}
$$

Set

$$
\begin{aligned}
\bar{B}(t, x) & =\int_{0}^{1} V^{\prime \prime}(t, \theta x) d \theta, \quad|x| \geq r \delta^{-1} \\
& =\bar{B}_{2}(t), \quad|x| \leq r \delta^{-1} .
\end{aligned}
$$

It follows that

$$
\bar{B}_{1}(t)-\epsilon I_{n} \leq \bar{B}(t, x) \leq \bar{B}_{2}(t)+\epsilon I_{n}
$$

for all $(t, x) \in[0,1] \times \mathbf{R}^{n}$. And $h(t, x)=V^{\prime}(t, x)-\bar{B}(t, x)=V^{\prime}(t, 0)\left(\right.$ as $\left.|x|>r \delta^{-1}\right)$ is bounded. If $i_{0, \pi}^{s}\left(\bar{B}_{1}\right)=i_{0, \pi}^{s}\left(\bar{B}_{2}\right), v_{0, \pi}^{s}\left(\bar{B}_{2}\right)=0$, then there exists $\epsilon>0$ such that $i_{0, \pi}^{s}\left(\bar{B}_{1}-\epsilon I_{n}\right)=i_{0, \pi}^{s}\left(\bar{B}_{2}+\epsilon I_{n}\right), v_{0, \pi}^{s}\left(\bar{B}_{2}+\epsilon I_{n}\right)=0$ via Proposition A.2(ii).

2. In (1.1) and $\left(V_{1}-V_{2}\right)$ if we replace $V^{\prime}(t, x)$ by $F \in C\left([0,1] \times \mathbf{R}^{n}, \mathbf{R}^{n}\right)$, the results in Theorem 1.2 are also valid.

3. Condition $\left(\mathrm{N}_{1}\right)$ is called the asymptotically linear condition; concerning other conditions like superlinear or sublinear conditions for operator equations we refer to [3].

The proof of Theorem 1.1 will be given in Section 2 and in Sections 3-6 we will investigate its other applications. Especially we will investigate differential systems with impulsive effects [4-16], which is not easy to investigate by variational methods. In the Appendix we recall some useful results concerning the index theory for linear self-adjoint operator equations in [2] which will be used in other sections.

\section{Proof of Theorem 1.1}

In this section we will prove Theorem 1.1. We need two lemmas about the Leray-Schauder degree. Suppose $X$ is a Banach space and $\Omega \subset X$ is a bounded open set. $T: \bar{\Omega} \rightarrow X$ is compact and $x-T x$ is not zero for all $x \in \partial \Omega$, so the Leray-Schauder degree $\operatorname{deg}(I d-T, \Omega) \in$ $\mathbf{Z}$ is defined. We have the following well-known lemmas.

\section{Lemma 2.1}

(i) If $\operatorname{deg}(I d-T, \Omega)$ is not zero, then there exists $x \in \Omega$ such that $x-T x=0$,

(ii) If $K$ is linear compact, $\operatorname{ker}(I d-K)=0$ and $0 \in \Omega$, then $\operatorname{deg}(I d-K, \Omega) \neq 0$,

(iii) $\operatorname{deg}\left(I d-T_{\lambda}, \Omega\right)$ is constant for $\lambda \in[0,1]$ provided $x-T_{\lambda} x$ is not zero for all $x \in \partial \Omega$ and $T_{\lambda} x=(1-\lambda) T_{0} x+\lambda T_{1} x$ and $T_{0}, T_{1}: \bar{\Omega} \rightarrow X$ are compact.

Lemma 2.2 Assume $K: X \rightarrow X$ is a linear compact operator, $1 \notin \sigma(K)$ the spectral of $K$. Let $\Omega$ be an open bounded subset of $X$ with $0 \in \Omega$. Then $\operatorname{deg}(I d-K, \Omega)=(-1)^{\beta}$ where $\beta=\sum_{\lambda_{j}>1, \lambda_{j} \in \sigma(K)} \beta_{j}$ and $\beta_{j}=\operatorname{dim} \operatorname{ker} \bigcup_{m=1}^{\infty}\left(K-\lambda_{j}\right)^{m}$. 
Proof of Theorem 1.1 Since $\left(\mathrm{N}_{1}\right)$ holds, $A^{-1} N+M$ is a compact operator on $Y$. Now we want to prove $\operatorname{deg}\left(I d-\left(A^{-1} N+M\right), U_{R}\right) \neq 0$ for some open ball $U_{R}$ in $Y$ with center 0 and radius $R>0$. It suffices to show that the possible solutions of the following equations are a priori bounded for $\lambda \in(0,1)$ with respect to the norm $\|\cdot\|_{Y}$ :

$$
x-\lambda\left(A^{-1} N(x)+M(x)\right)-(1-\lambda) A^{-1} B_{2} x=0 .
$$

If not, there exist $\left\{x_{j}\right\}_{j=1}^{\infty} \subset Y$ with $\left\|x_{j}\right\|_{Y} \rightarrow+\infty$, and $\left\{\lambda_{j}\right\}_{j=1}^{\infty} \subset(0,1)$ such that

$$
x_{j}-\lambda_{j}\left(A^{-1} N\left(x_{j}\right)+M\left(x_{j}\right)\right)-\left(1-\lambda_{j}\right) A^{-1} B_{2} x_{j}=0 .
$$

Set $y_{j}=x_{j} /\left\|x_{j}\right\|_{Y}$. Then (2.2) turns to

$$
y_{j}-\lambda_{j}\left(A^{-1} N\left(x_{j}\right)+M\left(x_{j}\right)\right) /\left\|x_{j}\right\|_{Y}-\left(1-\lambda_{j}\right) A^{-1} B_{2} y_{j}=0 .
$$

Because $\left\|y_{j}\right\|_{Y}=1,\left\{y_{j}\right\}$ is bounded in $X$. We may assume $y_{j} \rightarrow y_{0}$ in $Y$ and $y_{j} \rightarrow y_{0}$ in $X$ for some $y_{0} \in Y$ by going to subsequences if necessary. Further we claim

$$
B\left(x_{j}\right) y \rightarrow D_{1} y \text {. }
$$

in $X$ for any given $y \in X$ and some $D_{1} \in \mathcal{L}_{s}(X)$. In fact, by $\left(\mathrm{N}_{1}\right),\left\{\left\|B\left(x_{j}\right)\right\|\right\}$ is bounded, so it follows that

$$
B\left(x_{j}\right)\left(y_{j}-y_{0}\right) \rightarrow 0
$$

in $X$. Because $X$ is separable, there exists a countably orthonormal basis $\left\{e_{j}\right\}_{j=1}^{\infty}$. Since $\left\{B\left(x_{j}\right) e_{1}\right\}$ is bounded in $X$, we have $B\left(x_{j_{1}(i)}\right) e_{1} \rightarrow \xi_{1}$ in $X$, where $j_{1}(i)$ is a subsequence of the positive integer sequence. Now $\left\{B\left(x_{j_{1}(i)}\right) e_{2}\right\}$ is also bounded, again there exist a subsequence $j_{2}(i)$ of $j_{1}(i)$ and $\xi_{2} \in X$ such that $B\left(x_{j_{2}(i)}\right) e_{2} \rightarrow \xi_{2}$. Repeating this process and using the standard diagonal process, there exists a subsequence $j_{k}=j_{k}(k)$ such that $B\left(x_{j_{k}}\right) e_{l} \rightarrow \xi_{l}$ for any given $l$. Define a linear operator $D_{1}$ on $X$ by $D_{1} e_{j}=\xi_{j}$. Then $B\left(x_{j_{k}}\right) x \rightarrow$ $D_{1} x$ in $X$ for any given $x \in X$. So (2.4) holds. By assumptions, $A^{-1}: X \rightarrow X$ is compact, thus $A^{-1} B\left(x_{j}\right) y_{j} \rightarrow A^{-1} D_{1} y_{0}, A^{-1} B_{2} y_{j} \rightarrow A^{-1} B_{2} y_{0}$ in $X$ via (2.4) and (2.5). By $\left(\mathrm{N}_{1}\right)$, $\frac{A^{-} C\left(x_{j}\right)}{\left\|x_{j}\right\|_{Y}}+\frac{M\left(x_{j}\right)}{\left\|x_{j}\right\|_{Y}} \rightarrow 0$ in $X$. And from (2.3),

$$
\left(y, y_{j}\right)=\lambda_{j}\left(y, A^{-1} B\left(x_{j}\right) y_{j}+\frac{A^{-1} C\left(x_{j}\right)}{\left\|x_{j}\right\|_{Y}}+\frac{M\left(x_{j}\right)}{\left\|x_{j}\right\|_{Y}}\right)+\left(1-\lambda_{j}\right)\left(y, A^{-1} B_{2} y_{j}\right)
$$

for any $y \in X$. Further we assume $\lambda_{j} \rightarrow \lambda_{0}$. Taking the limit in (2.6) and considering (2.4) and (2.5) yield

$$
\left(y, y_{0}\right)=\left(y, \lambda_{0} A^{-1} D_{1} y_{0}+\left(1-\lambda_{0}\right) A^{-1} B_{2} y_{0}\right)
$$

for all $y \in X$ and

$$
A y_{0}-B_{3} y_{0}=0 \text {, }
$$


where $B_{3}=\lambda_{0} D_{1}+\left(1-\lambda_{0}\right) B_{2}$ satisfying $B_{1} \leq B_{3} \leq B_{2}$. By Proposition A.1(ii), $v_{A}\left(B_{3}\right)=0$. By the above argument and (2.3), $\left\{y_{j}\right\}$ is convergent in $Y$ by going to subsequence if necessary. So $\left\|y_{0}\right\|_{Y}=1$ and $y=y_{0}$ is a nontrivial solution of $A y-B_{3} y=0$, a contradiction. Thus, there is $R>0$ such that as $\|x\|_{Y} \geq R, x-\lambda\left(A^{-1} N(x)+M(x)\right)-(1-\lambda) A^{-1} B_{2} x \neq 0$ for all $\lambda \in$ $(0,1)$. So $\operatorname{deg}\left(I d-T_{\lambda}, U_{R}\right)$ is well defined where $T_{\lambda}=\lambda\left(A^{-1} N(x)+M(x)\right)+(1-\lambda) A^{-1} B_{2} x$. By Lemma 2.1(ii)-(iii), $\operatorname{deg}\left(I d-T_{1}, U_{R}\right)=\operatorname{deg}\left(I d-T_{0}, U_{R}\right) \neq 0$ because of $0 \in U_{R}$ and $\operatorname{ker}\{I d-$ $\left.A^{-1} B_{2}\right\}=\{0\}$ since $v_{A}\left(B_{2}\right)$. Hence, (1.5) has one solution.

Further assume $\left(\mathrm{N}_{2}\right)$ and $(\mathrm{M})$ hold. To obtain a nontrivial solution of (1.5), we claim that the following problem:

$$
x-\lambda\left(A^{-1} N(x)+M(x)\right)-(1-\lambda) A^{-1} B_{01} x=0
$$

has no solution $x$ satisfying $0<\|x\|_{Y} \leq r$.

If not, there exist $\left\{x_{k}\right\}_{k=1}^{\infty} \subset Y$ such that $\left\|x_{k}\right\|_{Y} \rightarrow 0$ and $\left\{\lambda_{k}\right\}_{k=1}^{\infty} \subset(0,1)$ such that

$$
x_{k}-\lambda_{k}\left(A^{-1} N\left(x_{k}\right)+M\left(x_{k}\right)\right)-\left(1-\lambda_{k}\right) A^{-1} B_{01} x_{k}=0 .
$$

We have

$$
x_{k}-\lambda_{k} M\left(x_{k}\right)-A^{-1} \tilde{B}_{k} x_{k}=0,
$$

where $\tilde{B}_{k}=\lambda_{k} B_{0}\left(x_{k}\right)+\left(1-\lambda_{k}\right) B_{01}$. Set $y_{k}=\frac{x_{k}}{\left\|x_{k}\right\|_{Y}}$. Then $\left\|y_{k}\right\|_{Y}=1, y_{k} \rightarrow y_{0}$ in $X$ and (2.7) turns to

$$
y_{k}-\frac{\lambda_{k} M\left(x_{k}\right)}{\left\|x_{k}\right\|_{Y}}-A^{-1} \tilde{B}_{k} y_{k}=0
$$

By (M), $\frac{M\left(x_{k}\right)}{\left\|x_{k}\right\|} \rightarrow 0$; and as before there exists a $D_{0} \in \mathcal{L}_{s}(X)$ satisfying $B_{01} \leq D_{0} \leq B_{02}$ such that $A^{-1} \tilde{B}_{k}\left(y_{k}\right) \rightarrow A^{-1} D_{0} y_{0}$ in $Y$. Taking the limit in (2.8) yields

$$
y_{0}-A^{-1} D_{0} y_{0}=0
$$

where $B_{01} \leq D_{0} \leq B_{02}$, so $v_{A}\left(D_{0}\right)=0$. As above we have $\left\|y_{0}\right\|_{Y}=1, y=y_{0}$ is a nontrivial solution of $A y_{0}-D_{0} y_{0}=0$, a contradiction. Now we prove

$$
\operatorname{deg}\left(I d-A^{-1} B_{01}, U_{r}\right)=(-1)^{I\left(0, B_{01}\right)} .
$$

By Proposition A.1, setting $K=A^{-1} B_{01}$ yields

$$
\sum_{\lambda>1, \lambda \in \sigma(K)} \operatorname{dim} \operatorname{ker}(K-\lambda)=\sum_{\lambda>1, \lambda \in \sigma(K)} v_{A}\left(\frac{1}{\lambda} B_{01}\right)=\sum_{\beta \in(0,1)} v\left(\beta B_{01}\right)=I_{A}\left(0, B_{01}\right) .
$$

By Lemma 2.2, in order to prove (2.9) we need only to show that $\operatorname{ker}(K-\lambda)=\operatorname{ker}(K-\lambda)^{2}$. In fact, assume $\operatorname{ker}(K-\lambda)^{2} x=0$. Then $\bar{x} \equiv(K-\lambda) x=\left(A^{-1}-\lambda B_{01}^{-1}\right) B_{01} x \in R\left(A^{-1}-\lambda B_{01}^{-1}\right)$ and $0=(K-\lambda) \bar{x}=\left(A^{-1}-\lambda B_{01}^{-1}\right) B_{01} \bar{x}$, so $B_{01} \bar{x} \in \operatorname{ker}\left(A^{-1}-\lambda B_{01}^{-1}\right)$. Because $A^{-1}-\lambda B_{01}^{-1}$ is self-adjoint, $\left(B_{01} \bar{x}, \bar{c}\right)=0$, and $\bar{x}=0$. 
By Lemmas 2.1-2.2 and (2.9),

$$
\operatorname{deg}\left(I d-\left(A^{-1} N+M\right), U_{r}\right)=\operatorname{deg}\left(I d-A^{-1} B_{01}, U_{r}\right)=(-1)^{I_{A}\left(0, B_{01}\right)}
$$

Similarly,

$$
\operatorname{deg}\left(I d-\left(A^{-1} N+M\right), U_{R}\right)=\operatorname{deg}\left(I d-A^{-1} B_{1}, U_{R}\right)=(-1)^{I_{A}\left(0, B_{1}\right)} .
$$

Hence

$$
\begin{aligned}
& \operatorname{deg}\left(I d-\left(A^{-1} N+M\right), U_{R} \backslash \bar{U}_{r}\right) \\
& \quad=\operatorname{deg}\left(I d-\left(A^{-1} N+M\right), U_{R}\right)-\operatorname{deg}\left(I d-\left(A^{-1} N+M\right), U_{r}\right) \\
& \quad=(-1)^{I_{A}\left(0, B_{1}\right)}-(-1)^{I_{A}\left(0, B_{01}\right)} \neq 0,
\end{aligned}
$$

since $I_{A}\left(0, B_{1}\right)-I_{A}\left(0, B_{01}\right)=i_{A}\left(B_{1}\right)-i_{A}\left(B_{01}\right)$ (via Proposition A.1(ii)) is odd. Therefore (1.5) has one solution $x$ with $\|x\|_{Y} \in(r, R]$.

Remark As $M(x)=0,(1.5)$ reduces to the equation

$$
A x=N(x)
$$

When $Y=D\left(|A|^{\frac{1}{2}}\right)$, Theorem 1.1 reduces to [2], Theorem 7.3.1, as $\sigma(A)=\sigma_{d}(A)$ is bounded from below, and to [2], Theorem 8.4.1, as $\sigma(A)=\sigma_{d}(A)$ is unbounded both from above and below.

\section{Applications to first order Hamiltonian systems}

Consider the following problem:

$$
\begin{aligned}
& \dot{x}=J H^{\prime}(t, x), \\
& x_{1}(0) \cos \alpha+x_{2}(0) \sin \alpha=M_{0}(x(0), x(1)), \\
& x_{1}(1) \cos \beta+x_{2}(1) \sin \beta=M_{1}(x(0), x(1)),
\end{aligned}
$$

where $H \in C^{1}\left([0,1] \times \mathbf{R}^{2 n}, \mathbf{R}^{2 n}\right)$ and $H^{\prime}(t, x)$ is the gradient of $H$ with respect to $x, x=$ $\left(x_{1}, x_{2}\right), x_{1}, x_{2} \in \mathbf{R}^{n}, \alpha \in[0, \pi), \beta \in(0, \pi], J$ is the standard symplectic matrix and $M_{i} \in$ $C\left(\mathbf{R}^{2 n} \times \mathbf{R}^{n}, \mathbf{R}^{2 n}\right)$ are bounded $(i=0,1) . x:[0,1] \rightarrow \mathbf{R}^{2 n}$ is said to be a solution of (3.1)-(3.3) if $x \in C^{1}\left([0,1], \mathbf{R}^{2 n}\right)$ and $x=x(t)$ satisfies (3.1)-(3.3).

We also make the following assumptions:

$\left(\mathrm{H}_{1}\right)$ There exists $\bar{B}:[0,1] \times \mathbf{R}^{2 n} \rightarrow \mathcal{L}_{s}\left(\mathbf{R}^{2 n}\right)$ with $\bar{B}(\cdot, x(\cdot)) \in L^{\infty}\left([0,1], \mathcal{L}_{s}\left(\mathbf{R}^{2 n}\right)\right)$ for all $x \in$ $C\left([0,1], \mathbf{R}^{2 n}\right), \bar{B}_{1}, \bar{B}_{2} \in L^{\infty}\left([0,1], \mathcal{L}_{s}\left(\mathbf{R}^{2 n}\right)\right)$ such that

$$
H^{\prime}(t, x)=\bar{B}(t, x) x+h(t, x), \quad \bar{B}_{1}(t) \leq \bar{B}(t, x) \leq \bar{B}_{2}(t)
$$

for all $(t, x) \in[0,1] \times \mathbf{R}^{2 n}$, and $h(t, x):[0,1] \times \mathbf{R}^{2 n} \rightarrow \mathbf{R}^{2 n}$ is bounded. 
$\left(\mathrm{H}_{2}\right)$ There exists $\bar{B}_{0}:[0,1] \times \mathbf{R}^{2 n} \rightarrow \mathcal{L}_{s}\left(\mathbf{R}^{2 n}\right)$ with $\bar{B}_{0}(\cdot, x(\cdot)) \in L^{\infty}\left([0,1], \mathcal{L}_{s}\left(\mathbf{R}^{2 n}\right)\right)$ for all $x \in C\left([0,1], \mathbf{R}^{2 n}\right), \bar{B}_{01}, \bar{B}_{02} \in L^{\infty}\left([0,1], \mathcal{L}_{s}\left(\mathbf{R}^{2 n}\right)\right)$ such that

$$
H^{\prime}(t, x)=\bar{B}_{0}(t, x) x, \quad \bar{B}_{01}(t) \leq \bar{B}_{0}(t, x) \leq \bar{B}_{02}(t)
$$

for all $(t, x) \in[0,1] \times \mathbf{R}^{2 n}$ with $|x| \leq r$ for some constant $r>0$.

Theorem 3.1 If $H$ satisfies $\left(\mathrm{H}_{1}\right)$ with $i_{\alpha, \beta}^{f}\left(\bar{B}_{1}\right)=i_{\alpha, \beta}^{f}\left(\bar{B}_{2}\right), v_{\alpha, \beta}^{f}\left(\bar{B}_{2}\right)=0$, then (3.1)-(3.3) has one solution. Furthermore, if $\left(\mathrm{H}_{2}\right)$ and $\left(\mathrm{M}_{1}\right)$ hold, then (3.1)-(3.3) has one nontrivial solution provided $i_{\alpha, \beta}^{f}\left(\bar{B}_{01}\right)=i_{\alpha, \beta}^{f}\left(\bar{B}_{02}\right), v_{\alpha, \beta}^{f}\left(\bar{B}_{02}\right)=0$ and $i_{\alpha, \beta}^{f}\left(\bar{B}_{01}\right)-i_{\alpha, \beta}^{f}\left(\bar{B}_{1}\right)$ is odd.

Proof Let $X=L^{2}\left([0,1], \mathbf{R}^{2 n}\right), Y=C\left([0,1], \mathbf{R}^{2 n}\right), D\left(A_{1}\right)=\left\{x \in H^{1}\left([0,1], \mathbf{R}^{2 n}\right) \mid x_{1}(0) \cos \alpha+\right.$ $\left.x_{2}(0) \sin \alpha=0, x_{1}(1) \cos \beta+x_{2}(1) \sin \beta=0\right\}, A_{1}: D\left(A_{1}\right) \subset Y \rightarrow X$ by $\left(A_{1} x\right)(t)=-J \dot{x}(t)-$ $\mu_{1} x(t)$ where $\mu_{1}<0, \mu_{1} \neq \beta-\alpha+k \pi, k \in \mathbf{Z}$ and $B_{1}-\mu_{1} I_{2 n} \geq I_{2 n}, B_{01}-\mu_{1} I_{2 n} \geq I_{2 n}$. Then $A_{1}$ is an unbounded self-adjoint and invertible operator in $X$ with $\sigma\left(A_{1}\right)=\sigma_{d}\left(A_{1}\right)=\left\{\beta-\alpha-\mu_{1}+\right.$ $k \pi \mid k \in \mathbf{Z}\} . N_{1}: Y \rightarrow Y$ by $\left(N_{1} x\right)(t)=H^{\prime}(t, x(t))-\mu_{1} x(t),(B(x) y)(t)=\bar{B}(t, x(t)) y(t)-\mu_{1} y(t)$. Hence $\left(\mathrm{H}_{1}\right),\left(\mathrm{H}_{2}\right)$ imply $\left(\mathrm{N}_{1}\right),\left(\mathrm{N}_{2}\right)$, respectively. Set $(A x)(t)=-J \dot{x}(t),\left(\widetilde{B}_{i} x\right)(t)=\bar{B}_{i}(t)-\mu_{1} x(t)$, $\left(\widetilde{B}_{0 i} x\right)(t)=\bar{B}_{0 i}(t)-\mu_{1} x(t)$ and $\left(B_{i} x\right)(t)=\bar{B}_{i}(t),\left(B_{0 i} x\right)(t)=\bar{B}_{0 i}(t)$; then $A_{1}=A-\mu_{1} I d, \tilde{B}_{i}=$ $B_{i}-\mu_{1} I d, \tilde{B}_{0 i}=B_{0 i}-\mu_{1} I d(i=1,2)$. By the definition in the Appendix, $v_{\alpha, \beta}^{f}\left(\bar{B}_{2}\right)=\nu_{A}\left(B_{2}\right)$, and

$$
\begin{aligned}
i_{A_{1}}\left(\tilde{B}_{2}\right)-i_{A_{1}}\left(\tilde{B}_{1}\right) & =\sum_{0 \leq \lambda<1} v_{A_{1}}\left((1-\lambda) \tilde{B}_{1}+\lambda \tilde{B}_{2}\right)=\sum_{0 \leq \lambda<1} v_{A}\left((1-\lambda) B_{1}+\lambda B_{2}\right) \\
& =i_{\alpha, \beta}^{f}\left(\bar{B}_{2}\right)-i_{\alpha, \beta}^{f}\left(\bar{B}_{1}\right) .
\end{aligned}
$$

Hence, $i_{\alpha, \beta}^{f}\left(\bar{B}_{2}\right)=i_{\alpha, \beta}^{f}\left(\bar{B}_{1}\right)$ implies $i_{A}\left(B_{2}\right)=i_{A}\left(B_{1}\right)$ and $i_{\alpha, \beta}^{f}\left(\bar{B}_{01}\right)-i_{\alpha, \beta}^{f}\left(\bar{B}_{1}\right)$ is odd means that $i_{A}\left(B_{01}\right)-i_{A}\left(B_{1}\right)$ is odd. Therefore, in order to finish the proof we need only to show that (3.1)-(3.3) can be written in the form of (1.5). Noticing that (3.1) is equivalent to

$$
x^{\prime}(t)-J \mu_{1} x(t)=J\left(H^{\prime}(t, x)-\mu_{1} x(t)\right) \equiv J f_{1}(t) .
$$

Multiplying the equation with the integral factor $e^{-J \mu_{1} t}$ and integrating over $[0, t]$, we can get

$$
x(t)=e^{J \mu_{1} t} x(0)+\int_{0}^{t} e^{J \mu_{1}(t-s)} J f_{1}(s) d s .
$$

Considering (3.2)-(3.3) yields

$$
\begin{aligned}
& x(0)=\frac{1}{\Delta_{1}}\left(\begin{array}{cc}
I_{n} \sin \left(\mu_{1}-\beta\right) & I_{n} \sin \alpha \\
I_{n} \cos \left(\mu_{1}-\beta\right) & -I_{n} \cos \alpha
\end{array}\right)\left(\begin{array}{c}
M_{0} \\
M_{1}
\end{array}\right) \\
& -\frac{1}{\Delta_{1}}\left(\begin{array}{c}
I_{n} \sin \alpha \\
-I_{n} \cos \alpha
\end{array}\right)\left(\begin{array}{ll}
I_{n} \cos \beta & I_{n} \sin \beta
\end{array}\right) \int_{0}^{1} e^{J \mu_{1}(1-s)} J f_{1}(s) d s,
\end{aligned}
$$

where $\Delta_{1}=\sin \left(\mu_{1}-\beta+\alpha\right)$. Then (3.1)-(3.3) is equivalent to

$$
x(t)=\int_{0}^{1} G_{1}(t, s) f_{1}(s) d s+M^{1}(x)=A_{1}^{-1} N_{1}(x)+M^{1}(x)
$$


where, as $0 \leq s \leq t \leq 1$,

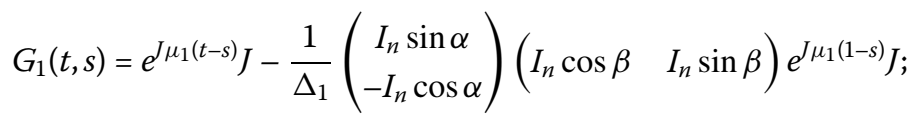

as $0 \leq t \leq s \leq 1$,

$$
G_{1}(t, s)=-\frac{1}{\Delta_{1}}\left(\begin{array}{c}
I_{n} \sin \alpha \\
-I_{n} \cos \alpha
\end{array}\right)\left(\begin{array}{ll}
I_{n} \cos \beta & I_{n} \sin \beta
\end{array}\right) e^{J \mu_{1}(1-s)} J
$$

and

$$
\left(M^{1} x\right)(t)=\frac{1}{\Delta_{1}}\left(\begin{array}{cc}
I_{n} \sin \left(\mu_{1}-\beta-\mu_{1} t\right) & I_{n} \sin \left(\alpha+\mu_{1} t\right) \\
I_{n} \cos \left(\mu_{1}-\beta-\mu_{1} t\right) & -I_{n} \cos \left(\alpha+\mu_{1} t\right)
\end{array}\right)\left(\begin{array}{c}
M_{0} \\
M_{1}
\end{array}\right) .
$$

It is easy to see that $M^{1}(x)$ is a compact operator satisfying $\left\|M^{1}(x)\right\|_{Y} \leq \rho$ for all $x \in Y$ and some $\rho>0$ and $\left(\mathrm{M}_{1}\right)$ implies (M). Hence Theorem 3.1 follows from Theorem 1.1.

As an application of Theorem 3.1 we investigate the following second order Hamiltonian systems:

$$
\begin{aligned}
& \ddot{x}+V^{\prime}(t, x)=0, \\
& x(0) \cos \alpha-x^{\prime}(0) \sin \alpha=M_{0}\left(x(0), x(1), x^{\prime}(0), x^{\prime}(1)\right), \\
& x(1) \cos \beta-x^{\prime}(1) \sin \beta=M_{1}\left(x(0), x(1), x^{\prime}(0), x^{\prime}(1)\right),
\end{aligned}
$$

where $V \in C^{1}\left([0,1] \times \mathbf{R}^{n}, \mathbf{R}\right), V^{\prime}$ denotes the gradient of $V$ with respect to $x, \alpha \in[0, \pi)$, $\beta \in(0, \pi], M_{0}, M_{1}: \mathbf{R}^{4 n} \rightarrow \mathbf{R}^{n}$ are continuous and bounded. $x:[0,1] \rightarrow \mathbf{R}^{n}$ is said to be a solution of (3.5)-(3.7) if $x \in C^{2}\left([0,1], \mathbf{R}^{n}\right)$ and $x=x(t)$ satisfies (3.5)-(3.7).

Corollary 3.1 If $V$ satisfies $\left(\mathrm{V}_{1}\right)$ with $i_{\alpha, \beta}^{s}\left(\bar{B}_{1}\right)=i_{\alpha, \beta}^{s}\left(\bar{B}_{2}\right), v_{\alpha, \beta}^{s}\left(\bar{B}_{2}\right)=0$, then (3.5)-(3.7) has one solution. Furthermore, if $\left(\mathrm{V}_{2}\right)$ and $\left(\mathrm{M}_{1}\right)$ hold, then (3.5)-(3.7) have one nontrivial solution provided $i_{\alpha, \beta}^{s}\left(\bar{B}_{01}\right)=i_{\alpha, \beta}^{s}\left(\bar{B}_{02}\right), v_{\alpha, \beta}^{s}\left(\bar{B}_{02}\right)=0$ and $i_{\alpha, \beta}^{s}\left(\bar{B}_{01}\right)-i_{\alpha, \beta}^{s}\left(\bar{B}_{1}\right)$ is odd.

Proof Define $y=-\dot{x}, z=(x, y), H(t, z)=\frac{1}{2}|y|^{2}+V(t, x)$. Then (3.5)-(3.7) are equivalent to (3.1)-(3.3). If $\left(\mathrm{V}_{1}\right)$ holds, then

$$
H^{\prime}(t, z)=\operatorname{diag}\left\{\bar{B}(t, x), I_{n}\right\} z+(h(t, x), 0) ;
$$

and if $\left(\mathrm{V}_{2}\right)$ holds, then

$$
H^{\prime}(t, z)=\operatorname{diag}\left\{\bar{B}_{0}(t, x), I_{n}\right\} z
$$

for all $(t, z) \in[0,1] \times \mathbf{R}^{2 n}$ with $|z| \leq r$. By Proposition A.2, $v_{\alpha, \beta}^{s}\left(\bar{B}_{01}\right)=v_{\alpha, \beta}^{f}\left(\operatorname{diag}\left\{\bar{B}_{01}, I_{n}\right\}\right)$, $v_{\alpha, \beta}^{s}\left(\bar{B}_{1}\right)=v_{\alpha, \beta}^{f}\left(\operatorname{diag}\left\{\bar{B}_{1}, I_{n}\right\}\right)$, and $i_{\alpha, \beta}^{s}\left(\bar{B}_{0 i}\right)=i_{\alpha, \beta}^{f}\left(\operatorname{diag}\left\{\bar{B}_{0 i}, I_{n}\right\}\right), i_{\alpha, \beta}^{s}\left(\bar{B}_{i}\right)=i_{\alpha, \beta}^{f}\left(\operatorname{diag}\left\{\bar{B}_{i}, I_{n}\right\}\right)(i=$ $1,2)$. Hence, the results follow from Theorem 3.1. 


\section{Remark}

1. When $\alpha=0, \beta=\pi$, (3.6)-(3.7) reduce to (1.2)-(1.3), so that Corollary 3.1 contains Theorem 1.2 as a special case.

2. When $M_{0}(\xi)=0, M_{1}(\xi)=0$ for $\xi \in \mathbf{R}^{4 n}$, the first part of Theorem 3.1 reduces [17], Theorem 3.4.3.

Next we discuss the problem

$$
\begin{aligned}
& \dot{x}=J H^{\prime}(t, x), \\
& x(1)-P x(0)=M_{2}(x(0), x(1)),
\end{aligned}
$$

where $P \in S_{p}\left(\mathbf{R}^{2 n}\right), M_{2}: \mathbf{R}^{2 n} \times \mathbf{R}^{2 n} \rightarrow \mathbf{R}^{2 n}$ is continuous and bounded. $x:[0,1] \rightarrow \mathbf{R}^{2 n}$ is said to be a solution of (3.1) and (3.8) if $x \in C^{1}\left([0,1], \mathbf{R}^{2 n}\right)$ and $x=x(t)$ satisfies (3.1) and (3.8). We will use the following assumption:

$\left(\mathrm{M}_{2}\right) M_{2}(\xi)=o(|\xi|)$ as $|\xi| \rightarrow 0$.

Theorem 3.2 If $H$ satisfies $\left(\mathrm{H}_{1}\right)$ with $i_{P}^{f}\left(\bar{B}_{1}\right)=i_{P}^{f}\left(\bar{B}_{2}\right), v_{P}^{f}\left(\bar{B}_{2}\right)=0$, then the problem (3.1) and (3.8) has one solution. Furthermore, if $\left(\mathrm{H}_{2}\right)$ and $\left(\mathrm{M}_{2}\right)$ hold, then the problem (3.1) and (3.8) has one nontrivial solution provided $i_{P}^{f}\left(\bar{B}_{01}\right)=i_{P}^{f}\left(\bar{B}_{02}\right), v_{P}^{f}\left(\bar{B}_{02}\right)=0$ and $i_{P}^{f}\left(\bar{B}_{01}\right)-i_{P}^{f}\left(\bar{B}_{1}\right)$ is odd.

Proof Let $X=L^{2}\left([0,1], \mathbf{R}^{2 n}\right), Y=C\left([0,1], \mathbf{R}^{2 n}\right)$. Define $D\left(A_{2}\right)=\left\{x \in H^{1}\left([0,1], \mathbf{R}^{2 n}\right) \mid x(1)=\right.$ $P x(0)\}$, and $A_{2}: D\left(A_{2}\right) \subset Y \rightarrow X$ by $\left(A_{2} x\right)(t)=-J \dot{x}(t)-\mu_{2} x(t)$ where we choose $\mu_{2}<0$ such that the operator $A_{2}$ is invertible, the matrix $\left(e^{J \mu_{2}}-P\right)$ is also invertible and $B_{1}-\mu_{2} I_{2 n} \geq I_{2 n}$, $B_{01}-\mu_{2} I_{2 n} \geq I_{2 n}$. Then $A_{2}$ is an unbounded self-adjoint and invertible operator in $X$ with $\sigma\left(A_{2}\right)=\sigma_{d}\left(A_{2}\right) . N_{2}: Y \rightarrow Y$ by $\left(N_{2} x\right)(t)=H^{\prime}(t, x(t))-\mu_{2} x(t) \equiv f_{2}(t)$.

Similar to the proof of Theorem 3.1, if $x=x(t)$ is a solution of (3.1) and (3.8), then

$$
x(t)=e^{J \mu_{2} t} x(0)+\int_{0}^{t} e^{J \mu_{2}(t-s)} J f_{2}(s) d s .
$$

Considering the boundary value condition (3.8) yields

$$
x(0)=\left(e^{J \mu_{2}}-P\right)^{-1}\left(M_{2}-\int_{0}^{1} e^{J \mu_{2}(1-s)} J f_{2}(s) d s\right) .
$$

Then the problem (3.1) and (3.8) is equivalent to

$$
x(t)=\int_{0}^{1} G_{2}(t, s) f_{2}(s) d s+M^{2}(x)=A_{2}^{-1} N_{2} x+M^{2}(x),
$$

where

$$
G_{2}(t, s)=-e^{J \mu_{2} t}\left(e^{J \mu_{2}}-P\right)^{-1} e^{J \mu_{2}(1-s)} J+e^{J \mu_{2}(t-s)} J
$$

for $0 \leq s \leq t \leq 1$;

$$
G_{2}(t, s)=-e^{J \mu_{2} t}\left(e^{J \mu_{2}}-P\right)^{-1} e^{J \mu_{2}(1-s)} J
$$


for $0 \leq t \leq s \leq 1$; and

$$
\left(M^{2} x\right)(t)=e^{J \mu_{2} t}\left(e^{J \mu_{2}}-P\right)^{-1} M_{2}(x(0), x(1)) .
$$

$M^{2}(x)$ is a compact operator and satisfies $\left\|M^{2}(x)\right\|_{Y} \leq \rho$ for some $\rho>0$. Hence $\left(\mathrm{H}_{1}\right),\left(\mathrm{H}_{2}\right)$, $\left(\mathrm{M}_{1}\right)$ imply $\left(\mathrm{N}_{1}\right),\left(\mathrm{N}_{2}\right),(\mathrm{M})$, respectively. Hence, Theorem 3.1 follows from Theorem 1.1.

Remark When $M_{2}(\xi)=0$ for $\xi \in \mathbf{R}^{4 n}$, the first part of Theorem 3.2 reduces to [17], Theorem 3.5.3.

\section{Applications to second order Hamiltonian systems}

We discuss the problem

$$
\begin{aligned}
& \ddot{x}+V^{\prime}(t, x)=0, \\
& x(1)-G x(0)=M_{0}\left(x(0), x(1), x^{\prime}(0), x^{\prime}(1)\right), \\
& x^{\prime}(1)-H x^{\prime}(0)=M_{1}\left(x(0), x(1), x^{\prime}(0), x^{\prime}(1)\right),
\end{aligned}
$$

where $M_{i}: \mathbf{R}^{4 n} \rightarrow \mathbf{R}^{n}(i=0,1)$ is continuous and bounded, $G, H \in G L(n), G^{T} H=I_{n}$. $x:[0,1] \rightarrow \mathbf{R}^{n}$ is said to be a solution of (4.1)-(4.3) if $x \in C^{2}\left([0,1], \mathbf{R}^{n}\right)$ and $x=x(t)$ satisfies (4.1)-(4.3).

Theorem 4.1 If $V$ satisfies $\left(\mathrm{V}_{1}\right)$ with $i_{M}^{s}\left(\bar{B}_{1}\right)=i_{M}^{s}\left(\bar{B}_{2}\right), v_{M}^{s}\left(\bar{B}_{2}\right)=0$, then (4.1)-(4.3) have one solution. Furthermore, if $\left(\mathrm{V}_{2}\right)$ and $\left(\mathrm{M}_{1}\right)$ hold, then (4.1)-(4.3) have one nontrivial solution provided $i_{M}^{s}\left(\bar{B}_{01}\right)=i_{M}^{s}\left(\bar{B}_{02}\right), v_{M}^{s}\left(\bar{B}_{02}\right)=0$ and $i_{M}^{s}\left(\bar{B}_{01}\right)-i_{M}^{s}\left(\bar{B}_{1}\right)$ is odd.

Proof Let $X=L^{2}\left([0,1], \mathbf{R}^{n}\right), D\left(A_{3}\right)=\left\{x \in H^{2}\left([0,1], \mathbf{R}^{n}\right) \mid x(1)=G x(0), x^{\prime}(1)=H x^{\prime}(0)\right\}, Y=$ $C^{1}\left([0,1], \mathbf{R}^{n}\right)$. The inclusion maps $D\left(A_{3}\right) \rightarrow Y, Y \rightarrow X$ are compact. Define $A_{3}: D\left(A_{3}\right) \rightarrow$ $L^{2}\left([0,1], \mathbf{R}^{n}\right)$ by $\left(A_{3} x\right)(t)=-\ddot{x}(t)+x(t)$. So $A_{3}$ is an unbounded self-adjoint operator in $X$ with $\sigma\left(A_{3}\right)=\sigma_{d}\left(A_{3}\right)$. Define $N_{3}: C^{1}\left([0,1], \mathbf{R}^{n}\right) \rightarrow L^{2}\left([0,1], \mathbf{R}^{n}\right)$ by $\left(N_{3} x\right)(t)=V^{\prime}(t, x(t))+$ $x(t) \equiv f_{3}(t)$. Then (4.1) is equivalent to

$$
\left(x^{\prime}(t)-x(t)\right)^{\prime}+\left(x^{\prime}(t)-x(t)\right)=-f_{3}(t)
$$

Multiplying the integral factor $e^{t}$ and integrating over $[0, t]$, we can get

$$
x^{\prime}(t)-x(t)=e^{-t}\left(x^{\prime}(0)-x(0)\right)-e^{-t} \int_{0}^{t} e^{\tau} f_{3}(\tau) d \tau .
$$

Multiplying the integral factor $e^{-t}$ and integrating over $[0, t]$ again yields

$$
x(t)=e^{t} x(0)+\operatorname{sh} t\left(x^{\prime}(0)-x(0)\right)-\int_{0}^{t} \operatorname{sh}(t-s) f_{3}(s) d s .
$$

Considering (4.2)-(4.3), we get the following system:

$$
\left\{\begin{array}{l}
\operatorname{sh} 1 x(0)+\left(\operatorname{ch} 1 I_{n}-H\right) x^{\prime}(0)=M_{0}+\int_{0}^{1} \operatorname{ch}(1-s) f_{3}(s) d s \\
\left(\operatorname{ch} 1 I_{n}-G\right) x(0)+\operatorname{sh} 1 x^{\prime}(0)=M_{1}+\int_{0}^{1} \operatorname{sh}(1-s) f_{3}(s) d s
\end{array}\right.
$$


The system is equivalent to

$$
\left(\begin{array}{cc}
K_{1} & 0 \\
0 & K_{2}
\end{array}\right)\left(\begin{array}{c}
x(0) \\
x^{\prime}(0)
\end{array}\right)=\left(\begin{array}{cc}
\operatorname{sh} 1 I_{n} & H-\operatorname{ch} 1 I_{n} \\
G-\operatorname{ch} 1 I_{n} & \operatorname{sh} 1 I_{n}
\end{array}\right)\left(\begin{array}{l}
M_{1}+\int_{0}^{1} \operatorname{ch}(1-s) f_{3}(s) d s \\
M_{0}+\int_{0}^{1} \operatorname{sh}(1-s) f_{3}(s) d s
\end{array}\right)
$$

where $K_{1}=-I_{n}+\operatorname{ch} 1(H+G)-H G, K_{2}=I_{n}+\operatorname{ch} 1(H+G)-G H$. Then

$$
\begin{aligned}
& x(0)=K_{1}^{-1}\left\{\operatorname{sh} 1 M_{1}+\int_{0}^{1}\left[\operatorname{sh} 1 \operatorname{ch}(1-s) I_{n}+\operatorname{sh}(1-s)\left(H-\operatorname{ch} 1 I_{n}\right)\right] f_{3}(s) d s\right\} \\
& x^{\prime}(0)=K_{2}^{-1}\left\{\left(G-\operatorname{ch} 1 I_{n}\right) M_{0}+\int_{0}^{1}\left[\operatorname{ch}(1-s)\left(G-\operatorname{ch} 1 I_{n}\right)+\operatorname{sh} 1 \operatorname{sh}(1-s) I_{n}\right] f_{3}(s) d s\right\} .
\end{aligned}
$$

Then (4.1)-(4.3) are equivalent to

$$
x(t)=\int_{0}^{1} G_{3}(t, s) f_{3}(s) d s+M^{3}(x)=A_{3}^{-1} N_{3} x+M^{3}(x),
$$

where

$$
\begin{aligned}
G_{3}(t, s)= & \operatorname{ch} t \operatorname{sh} 1 \operatorname{ch}(1-s) K_{1}^{-1}-\operatorname{ch} t \operatorname{sh}(1-s) K_{1}^{-1}\left(H-\operatorname{ch} 1 I_{n}\right) \\
& +\operatorname{sh} t \operatorname{ch}(1-s) K_{2}^{-1}\left(G-\operatorname{ch} 1 I_{n}\right)+\operatorname{sh} t \operatorname{sh} 1 \operatorname{sh}(1-s) K_{2}^{-1}-\operatorname{sh}(t-s) I_{n}
\end{aligned}
$$

for $0 \leq s \leq t \leq 1$;

$$
\begin{aligned}
G_{3}(t, s)= & -\operatorname{ch} t \operatorname{sh} 1 \operatorname{ch}(1-s) K_{1}^{-1}+\operatorname{ch} t \operatorname{sh}(1-s) K_{1}^{-1}\left(H-\operatorname{ch} 1 I_{n}\right) \\
& -\operatorname{sh} t \operatorname{ch}(1-s)\left(G-\operatorname{ch} 1 I_{n}\right)-\operatorname{sh} t \operatorname{sh} 1 \operatorname{sh}(1-s) K_{2}^{-1}
\end{aligned}
$$

for $0 \leq t \leq s \leq 1$, and

$$
\begin{aligned}
M^{3}(x)=[ & \left.\operatorname{ch} t K_{1}^{-1}\left(H-\operatorname{ch} 1 I_{n}\right)+\operatorname{sh} t \operatorname{sh} 1 K_{2}^{-1}\right] M_{0} \\
& +\left[\operatorname{ch} t \operatorname{sh} 1 K_{1}^{-1}+\operatorname{sh} t K_{2}^{-1}\left(G-\operatorname{ch} 1 I_{n}\right)\right] M_{1} .
\end{aligned}
$$

It is easy to check that $M^{3}(x)$ is a compact operator and satisfies $\left\|M^{3}(x)\right\|_{Y} \leq \rho$ for some $\rho>0$. Because $\left(V_{1}\right),\left(V_{2}\right),\left(M_{1}\right)$ imply $\left(N_{1}\right),\left(N_{2}\right),(M)$, Theorem 4.1 follows from Theorem 1.1.

\section{Applications to first order Hamiltonian system with impulses}

We first consider the following first order Hamiltonian system with impulses:

$$
\begin{aligned}
& \dot{x}=J H^{\prime}(t, x), \quad t \in(0,1), t \neq t_{i}, i=1,2, \ldots, p, \\
& \Delta x\left(t_{i}\right)=I_{i}\left(x\left(t_{i}-0\right)\right), \quad i=1,2, \ldots, p, \\
& x_{1}(0) \cos \alpha+x_{2}(0) \sin \alpha=M_{0}(x(0), x(1)), \\
& x_{1}(1) \cos \beta+x_{2}(1) \sin \beta=M_{1}(x(0), x(1)),
\end{aligned}
$$


where $\Delta x\left(t_{i}\right)=x\left(t_{i}+0\right)-x\left(t_{i}-0\right), x=\left(x_{1}, x_{2}\right), x_{1}, x_{2} \in \mathbf{R}^{n}$ and $I_{i}: \mathbf{R}^{2 n} \rightarrow \mathbf{R}^{2 n}, M_{0}, M_{1}$ : $\mathbf{R}^{2 n} \times \mathbf{R}^{2 n} \rightarrow \mathbf{R}^{n}$ are continuous and bounded. $x:[0,1] \rightarrow \mathbf{R}^{2 n}$ is said to be a solution of (5.1)-(5.4) if $x \in C^{1}\left([0,1] \backslash\left\{t_{i}\right\}_{i=1}^{p}, \mathbf{R}^{2 n}\right), x\left(t_{i}+0\right), x\left(t_{i}-0\right)$ exist and $x=x(t)$ satisfies (5.1)-(5.4). We need the following assumption:n

(I) $I_{i}(\xi)=o(|\xi|)$ as $|\xi| \rightarrow 0(i=1,2, \ldots, p)$.

Theorem 5.1 If H satisfies $\left(\mathrm{H}_{1}\right)$ with $i_{\alpha, \beta}^{f}\left(\bar{B}_{1}\right)=i_{\alpha, \beta}^{f}\left(\bar{B}_{2}\right), v_{\alpha, \beta}^{f}\left(\bar{B}_{2}\right)=0$, then (5.1)-(5.4) have one solution. Furthermore, if $\left(\mathrm{H}_{2}\right),\left(\mathrm{M}_{1}\right)$ and $(\mathrm{I})$ hold, then (5.1)-(5.4) have one nontrivial solution provided $i_{\alpha, \beta}^{f}\left(\bar{B}_{01}\right)=i_{\alpha, \beta}^{f}\left(\bar{B}_{02}\right), v_{\alpha, \beta}^{f}\left(\bar{B}_{02}\right)=0$ and $i_{\alpha, \beta}^{f}\left(\bar{B}_{01}\right)-i_{\alpha, \beta}^{f}\left(\bar{B}_{1}\right)$ is odd.

Proof Let $X=L^{2}\left([0,1], \mathbf{R}^{2 n}\right), Y=C\left(0,1, t_{i} ; \mathbf{R}^{2 n}\right)=\left\{x:[0,1] \rightarrow \mathbf{R}^{2 n} \mid x(t)\right.$ is continuous for $t \in$ $[0,1] \backslash\left\{t_{i}\right\}_{i=1}^{p}, x\left(t_{i}+0\right), x\left(t_{i}-0\right)$ exist, $\left.x\left(t_{i}\right)=x\left(t_{i}-0\right), i=1,2, \ldots, p\right\}$, As in the proof of Theorem 3.1, (5.1)-(5.4) are equivalent to

$$
x=A_{1}^{-1} N_{1} x+M^{4}(x)
$$

where $A_{1}, N_{1}$ are defined as in Theorem 3.1 and

$$
\begin{aligned}
M^{4}(x)= & \left(M^{1} x\right)(t) \\
& +\frac{1}{\Delta_{1}} e^{J \mu_{2} t}\left(\begin{array}{c}
I_{n} \sin \alpha \\
-I_{n} \cos \alpha
\end{array}\right)\left(\begin{array}{c}
I_{n} \sin \alpha \\
-I_{n} \cos \alpha
\end{array}\right)\left(I_{n} \cos \beta \quad I_{n} \sin \beta\right) \sum_{i=1}^{p} e^{J \mu_{2}\left(1-t_{i}\right)} I_{i}\left(x\left(t_{i}\right)\right) \\
& +\sum_{t>t_{i}} e^{J \mu_{2}\left(t-t_{i}\right)} I_{i}\left(x\left(t_{i}\right)\right) .
\end{aligned}
$$

Hence Theorem 5.1 follows from Theorem 1.1.

As an application of Theorem 5.1 we investigate the following second order Hamiltonian systems with impulses:

$$
\begin{aligned}
& \ddot{x}+V^{\prime}(t, x)=0, \quad t \in(0,1), t \neq t_{i}, i=1,2, \ldots, p, \\
& \Delta x\left(t_{i}\right)=I_{i}\left(x\left(t_{i}-0\right)\right), \quad \Delta x^{\prime}\left(t_{i}\right)=J_{i}\left(x^{\prime}\left(t_{i}-0\right)\right), \quad i=1,2, \ldots, p, \\
& x(0) \cos \alpha-x^{\prime}(0) \sin \alpha=M_{0}\left(x(0), x^{\prime}(0), x(1), x^{\prime}(1)\right), \\
& x(1) \cos \beta-x^{\prime}(1) \sin \beta=M_{1}\left(x(0), x^{\prime}(0), x(1), x^{\prime}(1)\right),
\end{aligned}
$$

where $\Delta x^{\prime}\left(t_{i}\right)=x^{\prime}\left(t_{i}+0\right)-x^{\prime}\left(t_{i}-0\right)$ and $M_{0}, M_{1}: \mathbf{R}^{4 n} \rightarrow \mathbf{R}^{n}, I_{i}, J_{i}: \mathbf{R}^{n} \rightarrow \mathbf{R}^{n}(i=1,2, \ldots, p)$ are continuous and bounded. $x:[0,1] \rightarrow \mathbf{R}^{n}$ is said to be a solution of (5.5)-(5.8) if $x \in$ $C^{2}\left([0,1] \backslash\left\{t_{i}\right\}_{i=1}^{p}, \mathbf{R}^{n}\right), x\left(t_{i}+0\right), x\left(t_{i}-0\right), x^{\prime}\left(t_{i}+0\right), x^{\prime}\left(t_{i}-0\right)$ exist, $x\left(t_{i}\right)=x\left(t_{i}-0\right)$ and $x=x(t)$ satisfies (5.5)-(5.8). We need the following assumption:

(J) $J_{i}(\xi)=o(|\xi|)$ as $|\xi| \rightarrow 0(i=1,2, \ldots, p)$.

Corollary 5.1 If $V$ satisfies $\left(\mathrm{V}_{1}\right)$ with $i_{\alpha, \beta}^{s}\left(\bar{B}_{1}\right)=i_{\alpha, \beta}^{s}\left(\bar{B}_{2}\right), v_{\alpha, \beta}^{s}\left(\bar{B}_{2}\right)=0$, then (5.5)-(5.8) have one solution. Furthermore, if $\left(\mathrm{V}_{2}\right),\left(\mathrm{M}_{1}\right)$, (I) and $(\mathrm{J})$ hold, then (5.5)-(5.8) have one nontrivial solution provided $i_{\alpha, \beta}^{s}\left(\bar{B}_{01}\right)=i_{\alpha, \beta}^{s}\left(\bar{B}_{02}\right), v_{\alpha, \beta}^{s}\left(\bar{B}_{02}\right)=0$ and $i_{\alpha, \beta}^{s}\left(\bar{B}_{01}\right)-i_{\alpha, \beta}^{s}\left(\bar{B}_{1}\right)$ is odd. 
Proof Similar to the proof of Corollary 3.1. Then we consider the problem

$$
\begin{aligned}
& \dot{x}=J H^{\prime}(t, x), \quad t \in(0,1), t \neq t_{i}, i=1,2, \ldots, p, \\
& \Delta x\left(t_{i}\right)=I_{i}\left(x\left(t_{i}-0\right)\right), \quad i=1,2, \ldots, p, \\
& x(1)-P x(0)=M_{2}(x(0), x(1)),
\end{aligned}
$$

where $I_{i}: \mathbf{R}^{2 n} \rightarrow \mathbf{R}^{2 n}(i=1,2, \ldots, p), M_{2}: \mathbf{R}^{2 n} \times \mathbf{R}^{2 n} \rightarrow \mathbf{R}^{2 n}$ is continuous and bounded. $x:[0,1] \rightarrow \mathbf{R}^{n}$ is said to be a solution of (5.1), (5.2) and (5.9) if $x \in C^{1}\left([0,1] \backslash\left\{t_{i}\right\}_{i=1}^{p}, \mathbf{R}^{2 n}\right)$, $x\left(t_{i}+0\right), x\left(t_{i}-0\right)$ exist, $x\left(t_{i}\right)=x\left(t_{i}-0\right)$ and $x=x(t)$ satisfies (5.1), (5.2) and (5.9).

Theorem 5.2 If $H$ satisfies $\left(\mathrm{H}_{1}\right)$ with $i_{P}^{f}\left(\bar{B}_{1}\right)=i_{P}^{f}\left(\bar{B}_{2}\right), v_{P}^{f}\left(\bar{B}_{2}\right)=0$, then the system (5.1), (5.2) and (5.9) has one solution. Furthermore, if $\left(\mathrm{H}_{2}\right),\left(\mathrm{M}_{2}\right)$ and $(\mathrm{I})$ hold, then the system (5.1), (5.2) and (5.9) has one nontrivial solution provided $i_{P}^{f}\left(\bar{B}_{01}\right)=i_{P}^{f}\left(\bar{B}_{02}\right), v_{P}^{f}\left(\bar{B}_{02}\right)=0$ and $i_{P}^{f}\left(\bar{B}_{01}\right)-i_{P}^{f}\left(\bar{B}_{1}\right)$ is odd.

Proof Let $X, Y$ be defined in the proof of Theorem 5.1, and let $D\left(A_{2}\right)$ and $A_{2}$ be defined in the proof of Theorem 3.2. Then (5.1), (5.2) and (5.9) are equivalent to

$$
x(t)=A_{2}^{-1} N_{2} x+M^{5}(x),
$$

where $A_{2}, N_{2}$ are defined as in Theorem 3.2 and

$$
\begin{aligned}
M^{5}(x)= & e^{J \mu_{2} t}\left(e^{J \mu_{2}}-P\right)^{-1} M_{2}-e^{J \mu_{2} t}\left(e^{J \mu_{2}}-P\right)^{-1} e^{J \mu_{2}} \sum_{1>t_{i}} e^{-J \mu_{2} t_{i}} I_{i} \\
& +e^{J \mu_{2} t} \sum_{t>t_{i}} e^{-J \mu_{2} t_{i}} I_{i}\left(x\left(t_{i}\right)\right) .
\end{aligned}
$$

It is easy to check that $M^{5}(x): Y \rightarrow Y$ is a compact operator and satisfies $\left\|M^{5}(x)\right\|_{Y} \leq \rho$ for some $\rho>0$.

\section{Applications to second order Hamiltonian system with impulses}

Consider the second order Hamiltonian system with impulses

$$
\begin{aligned}
& \ddot{x}+V^{\prime}(t, x)=0, \quad t \in(0,1), t \neq t_{i}, i=1,2, \ldots, p, \\
& \Delta x\left(t_{i}\right)=I\left(x_{i}\left(t_{i}-0\right)\right), \quad \Delta x^{\prime}\left(t_{i}\right)=J_{i}\left(x^{\prime}\left(t_{i}-0\right)\right), \quad i=1,2, \ldots, p, \\
& x(1)-G x(0)=M_{0}\left(x(0), x(1), x^{\prime}(0), x^{\prime}(1)\right), \\
& x^{\prime}(1)-H x^{\prime}(0)=M_{1}\left(x(0), x(1), x^{\prime}(0), x^{\prime}(1)\right),
\end{aligned}
$$

where $\Delta x\left(t_{i}\right)=x\left(t_{i}+0\right)-x\left(t_{i}-0\right), \Delta x^{\prime}\left(t_{i}\right)=x^{\prime}\left(t_{i}+0\right)-x^{\prime}\left(t_{i}-0\right), I_{i}, J_{i}: \mathbf{R}^{n} \rightarrow \mathbf{R}^{n}(i=$ $1,2, \ldots, p), M_{i}: \mathbf{R}^{4 n} \rightarrow \mathbf{R}^{n}(i=0,1)$ are continuous and bounded and $G, H \in G L(n), G^{T} H=$ $I_{n} \cdot x:[0,1] \rightarrow \mathbf{R}^{n}$ is said to be a solution of (6.1)-(6.4) if $x \in C^{2}\left([0,1] \backslash\left\{t_{i}\right\}_{i=1}^{p}, \mathbf{R}^{n}\right), x\left(t_{i}+0\right)$, $x\left(t_{i}-0\right), x^{\prime}\left(t_{i}+0\right), x^{\prime}\left(t_{i}-0\right)$ exist, $x\left(t_{i}\right)=x\left(t_{i}-0\right)$ and $x=x(t)$ satisfies (6.1)-(6.4).

Theorem 6.1 If $V$ satisfies $\left(V_{1}\right)$ with $i_{M}^{s}\left(\bar{B}_{1}\right)=i_{M}^{s}\left(\bar{B}_{2}\right), v_{M}^{s}\left(\bar{B}_{2}\right)=0$, then (6.1)-(6.4) has one solution. Furthermore, if $\left(\mathrm{V}_{2}\right),\left(\mathrm{M}_{1}\right)$, (I) and (J) hold, then (6.1)-(6.4) has one nontrivial solution provided $i_{M}^{s}\left(\bar{B}_{01}\right)=i_{M}^{s}\left(\bar{B}_{02}\right), v_{M}^{s}\left(\bar{B}_{02}\right)=0$ and $i_{M}^{s}\left(\bar{B}_{01}\right)-i_{M}^{s}\left(\bar{B}_{1}\right)$ is odd. 
Proof Let $X=L^{2}\left([0,1], \mathbf{R}^{n}\right), Y=C^{1}\left(0,1, t_{i} ; \mathbf{R}^{n}\right)=\left\{x:[0,1] \rightarrow \mathbf{R}^{n} \mid x^{\prime}(t)\right.$ is continuous for $t \in$ $[0,1] \backslash\left\{t_{i}\right\}_{i=1}^{p}, x^{\prime}\left(t_{i}+0\right), x^{\prime}\left(t_{i}-0\right)$ exist, $\left.x\left(t_{i}\right)=x\left(t_{i}-0\right), x^{\prime}\left(t_{i}\right)=x^{\prime}\left(t_{i}-0\right), i=1, \ldots, p\right\}$, and let $D\left(A_{3}\right), A_{3}$ be defined in the proof of Theorem 4.1. Then (6.1)-(6.4) are equivalent to

$$
x(t)=\int_{0}^{1} G_{3}(t, s) f_{3}(s) d s+M^{6}(x)=A_{3}^{-1} N_{3}(x)+M^{6}(x),
$$

where $G_{3}(t, x), f_{3}(s)$ are defined in the proof of Theorem 4.1. We have

$$
\begin{aligned}
M^{6}(x)= & M^{3}(x)+\left(\operatorname{sh} t K_{2}^{-1}-\operatorname{sh} 1 \operatorname{ch} t K_{1}^{-1}\right) \Delta_{3}+\left[\operatorname{sh} 1 \operatorname{sh} t K_{2}^{-1}-\operatorname{ch} t K_{1}^{-1}\left(H-\operatorname{ch} 1 I_{n}\right)\right] \Delta_{4} \\
& +e^{t} \sum_{t_{i}<t} e^{t_{i}} I_{i}+e^{t} \int_{0}^{t} e^{-2 s} \sum_{t_{i}<s} e^{t_{i}}\left(J_{i}-I_{i}\right) d s
\end{aligned}
$$

and

$$
\begin{aligned}
& \Delta_{3}=-\sum_{i=1}^{p} 2 \operatorname{sh}\left(1-t_{i}\right) I_{i}-\sum_{i=1}^{p} e^{-1+t_{i}} J_{i}-\int_{0}^{1} e^{1-2 s} \sum_{i=1}^{p} e^{t_{i}}\left(J_{i}-I_{i}\right) d s, \\
& \Delta_{4}=\sum_{i=1}^{p} e^{-1+t_{i}} I_{i}-\int_{0}^{1} e^{1-2 s} \sum_{i=1}^{p} e^{t_{i}}\left(J_{i}-I_{i}\right) d s .
\end{aligned}
$$

Hence Theorem 6.1 follows from Theorem 1.1.

\section{Appendix}

In this section we will recall some results concerning index theory for self-adjoint operator equations from Dong $[2,17]$. For index theories for Hamiltonian systems and symplectic paths we refer to $[18,19]$. Let $X$ be an infinite-dimensional Hilbert space, and let $A$ be an unbounded self-adjoint invertible operator satisfying $\sigma(A)=\sigma_{d}(A)$. For any $B_{1}, B_{2} \in \mathcal{L}_{s}(X)$, we write $B_{1}<B_{2}$ w.r.t. $X_{1}$ (a subspace of $X$ ) if and only if $\left(B_{1} x, x\right)<\left(B_{2} x, x\right)$ for all $x \in X_{1} \backslash\{0\}$; and write $B_{1} \leq B_{2}$ w.r.t. $X_{1}$ if and only if $\left(B_{1} x, x\right) \leq\left(B_{2} x, x\right)$ for all $x \in X_{1}$. If $X=X_{1}$ we just write $B_{1}<B_{2}$ or $B_{1} \leq B_{2}$.

\section{Definition A.1}

(i) For any $B \in \mathcal{L}_{s}(X)$, the space of bounded self-adjoint operators on $X$, we define $v_{A}(B)=\operatorname{dim} \operatorname{ker}(A-B), v_{A}(B)$ is called the nullity of $B$.

(ii) For any $B_{1}, B_{2} \in \mathcal{L}_{s}(X)$ with $B_{1}<B_{2}$, we define

$$
I_{A}\left(B_{1}, B_{2}\right)=\sum_{\lambda \in[0,1)} v_{A}\left((1-\lambda) B_{1}+\lambda B_{2}\right)
$$

and for any $B_{1}, B_{2} \in \mathcal{L}_{s}(X)$ we define

$$
I_{A}\left(B_{1}, B_{2}\right)=I_{A}\left(B_{1}, k I d\right)-I_{A}\left(B_{2}, k I d\right),
$$

where $I d: X \rightarrow X$ is the identity map and $k I d>B_{1}, k I d>B_{2}$ for some real number $k>0$. 
(iii) For any $B \in \mathcal{L}_{s}(X)$, we define

$$
i_{A}(B)=i_{A}\left(B_{0}\right)+I_{A}\left(B_{0}, B\right)
$$

where $B_{0} \in \mathcal{L}_{s}(X)$ is fixed and $i_{A}\left(B_{0}\right)$ is a prescribed integer.

\section{Proposition A.1}

(i) For any $B \in \mathcal{L}_{s}(X),\left(v_{A}(B), i_{A}(B)\right) \in \mathbf{N} \times \mathbf{Z}$.

(ii) For any $B_{1}, B_{2} \in \mathcal{L}_{s}(X)$, if $B_{1} \leq B_{2}$, then $i_{A}\left(B_{1}\right) \leq i_{A}\left(B_{2}\right)$, $v_{A}\left(B_{1}\right)+i_{A}\left(B_{1}\right) \leq v_{A}\left(B_{2}\right)+i_{A}\left(B_{2}\right)$; if $B_{1} \leq B_{2}$, and $B_{1}<B_{2}$ with respect to $\operatorname{ker}\left(A-B_{1}\right)$, then $v_{A}\left(B_{1}\right)+i_{A}\left(B_{1}\right) \leq i_{A}\left(B_{2}\right)$.

(iii) If $\inf \sigma(A) \geq \lambda_{0}$ for some $\lambda_{0} \in \mathbf{R}$, we can choose $B_{0}=\lambda_{0} I d$ and $i_{A}\left(B_{0}\right)=0$, then the index defined by Definition A.1 satisfies

$$
i_{A}(B)=\sum_{\lambda<0} v_{A}(B+\lambda I d)
$$

Define $X_{1}=L^{2}\left([0,1], \mathbf{R}^{2 n}\right)$,

$D\left(A_{1}\right)=\left\{x \in H^{2}\left([0,1], \mathbf{R}^{2 n}\right) \mid x_{1}(0) \cos \alpha+x_{2}(0) \sin \alpha=0, x_{1}(1) \cos \beta+x_{2}(1) \sin \beta=0\right\}$ and $\left(A_{1} x\right)(t)=-J \dot{x}(t)$ for all $x \in D\left(A_{1}\right)$. For any $\bar{B}_{1}, \bar{B}_{2} \in L^{\infty}\left([0,1], \mathcal{L}_{s}\left(\mathbf{R}^{n}\right)\right)$, we define $\bar{B}_{1} \leq \bar{B}_{2}$ if and only if $\bar{B}_{1}(t) \leq \bar{B}_{2}(t)$ for a.e. $t \in[0,1]$; and define $\bar{B}_{1}<\bar{B}_{2}$ if and only if $\bar{B}_{1} \leq \bar{B}_{2}$ and $\bar{B}_{1}(t) \leq \bar{B}_{2}(t)$ on a subset of $(0,1)$ with positive measure. For $\bar{B} \in L^{\infty}\left([0,1], \mathcal{L}_{s}\left(\mathbf{R}^{n}\right)\right)$ we define $(B x)(t)=\bar{B}(t) x(t)$ for all $x \in X_{1}$. It is easy to check that $\bar{B}_{1} \leq \bar{B}_{2}$ means that $B_{1}<B_{2}$ w.r.t. $\operatorname{ker}\left(A_{1}-B_{1}\right)$.

Definition A.2 For any $\bar{B} \in L^{\infty}\left([0,1], \mathcal{L}_{s}\left(\mathbf{R}^{2 n}\right)\right)$, we define

$$
\begin{aligned}
& v_{\alpha, \beta}^{f}(\bar{B})=\operatorname{dim} \operatorname{ker}\left(A_{1}-B\right), \\
& i_{\alpha, \beta}^{f}\left(I_{2 n}\right)=i_{\alpha, \beta}^{s}\left(I_{n}\right), \\
& i_{\alpha, \beta}^{f}(\bar{B})=i_{\alpha, \beta}^{f}\left(I_{2 n}\right)+I_{\alpha, \beta}^{f}\left(I_{2 n}, \bar{B}\right),
\end{aligned}
$$

where $i_{\alpha, \beta}^{s}\left(I_{n}\right)$ will be defined in Definition A.4, and as $\bar{B}_{1}<\bar{B}_{2}$ and

$$
I_{\alpha, \beta}^{f}\left(\bar{B}_{1}, \bar{B}_{2}\right)=\sum_{\lambda \in[0,1)} v_{\alpha, \beta}^{f}\left((1-\lambda) \bar{B}_{1}+\lambda \overline{B_{2}}\right)
$$

and for any $\bar{B}_{1}, \bar{B}_{2} \in L^{\infty}\left([0,1], \mathcal{L}_{s}\left(\mathbf{R}^{2 n}\right)\right)$, we define

$$
I_{\alpha, \beta}^{f}\left(\bar{B}_{1}, \bar{B}_{2}\right)=I_{\alpha, \beta}^{f}\left(\bar{B}_{1}, k I_{2 n}\right)-I_{\alpha, \beta}^{f}\left(\bar{B}_{2}, k I_{2 n}\right)
$$

where $k \in \mathbf{R}, k I_{2 n}>\bar{B}_{1}, k I_{2 n}>\bar{B}_{2}$.

Define $X_{2}=L^{2}\left([0,1], \mathbf{R}^{2 n}\right), D\left(A_{2}\right)=\left\{x \in H^{2}\left([0,1], \mathbf{R}^{2 n}\right) \mid x(1)=P x(0)\right\}, P \in S_{p}(2 n)$ and $\left(A_{2} x\right)(t)=-J \dot{x}(t)$ for all $x \in D\left(A_{2}\right)$. 


\section{Definition A.3}

(i) For any $\bar{B} \in L^{\infty}\left([0,1], \mathcal{L}_{s}\left(\mathbf{R}^{2 n}\right)\right)$, we define

$$
\nu_{P}^{f}(\bar{B})=\operatorname{dim} \operatorname{ker}\left(A_{2}-B\right) .
$$

(ii) For any $\bar{B}_{1}, \bar{B}_{2} \in L^{\infty}\left([0,1], \mathcal{L}_{s}\left(\mathbf{R}^{2 n}\right)\right)$ with $\bar{B}_{1}<\bar{B}_{2}$, we define

$$
I_{P}^{f}\left(\bar{B}_{1}, \bar{B}_{2}\right)=\sum_{s \in[0,1)} v_{P}^{f}\left((1-s) \bar{B}_{1}+s \bar{B}_{2}\right)
$$

and if $\bar{B}_{1}<\bar{B}_{2}$ does not hold, we define

$$
I_{P}^{f}\left(\bar{B}_{1}, \bar{B}_{2}\right)=I_{P}^{f}\left(\bar{B}_{1}, c I_{2 n}\right)-I_{P}^{f}\left(\bar{B}_{2}, c I_{2 n}\right),
$$

where $c \in \mathbf{R}$ such that $c I_{2 n}>\bar{B}_{1}$ and $c I_{2 n}>\bar{B}_{2}$.

(iii) For any $\bar{B} \in L^{\infty}\left([0,1], \mathcal{L}_{s}\left(\mathbf{R}^{2 n}\right)\right)$, we define

$$
i_{P}^{f}(\bar{B})=i_{P}^{f}(0)+I_{P}^{f}(0, \bar{B})
$$

where $i_{P}^{f}(0) \in \mathbf{Z}$ is prescribed and depends only on $P$.

Define $X_{3}=L^{2}\left([0,1], \mathbf{R}^{n}\right)$,

$D\left(A_{3}\right)=\left\{x \in H^{2}\left([0,1], \mathbf{R}^{n}\right) \mid x(0) \cos \alpha-x^{\prime}(0) \sin \alpha=0, x(1) \cos \beta-x^{\prime}(0) \sin \beta=0\right\}$ for some constants $\alpha \in[0, \pi), \beta \in(0, \pi]$ and $\left(A_{3} x\right)(t)=\ddot{x}(t)$ for all $x \in D\left(A_{3}\right)$.

Definition A.4 For any $\bar{B} \in L^{\infty}\left([0,1], \mathcal{L}_{s}\left(\mathbf{R}^{n}\right)\right)$, we define

$$
\begin{aligned}
& v_{\alpha, \beta}^{s}(\bar{B})=\operatorname{dim} \operatorname{ker}\left(A_{3}-B\right), \\
& i_{\alpha, \beta}^{s}(\bar{B})=\sum_{\lambda<0} v_{\alpha, \beta}^{s}\left(\bar{B}+\lambda I_{n}\right),
\end{aligned}
$$

where $(B x)(t)=\bar{B}(t) x(t)$ for all $x \in X$.

Define $X_{4}=L^{2}\left([0,1], \mathbf{R}^{n}\right), D\left(A_{4}\right)=\left\{x \in H^{2}\left([0,1], \mathbf{R}^{n}\right) \mid x(1)=M x(0), x^{\prime}(1)=N x^{\prime}(0)\right\}$ where $M, N \in G L(n), M^{T} N=I_{n}$, and define $\left(A_{4} x\right)(t)=-\ddot{x}(t)$.

Definition A.5 For any $\bar{B} \in L^{\infty}\left([0,1], \mathcal{L}_{s}\left(\mathbf{R}^{n}\right)\right)$, we define

$$
\begin{aligned}
& v_{M}^{s}(\bar{B})=\operatorname{dim} \operatorname{ker}\left(A_{4}-B\right), \\
& i_{M}^{s}(\bar{B})=\sum_{\lambda<0} v_{M}^{s}\left(\bar{B}+\lambda I_{n}\right) .
\end{aligned}
$$

\section{Proposition A.2}

(i) For any $\bar{B}_{1}, \bar{B}_{2} \in L^{\infty}\left([0,1], \mathcal{L}_{s}\left(\mathbf{R}^{n}\right)\right)$, if $\bar{B}_{1} \leq \bar{B}_{2}$, then $i_{\alpha, \beta}^{s}\left(\bar{B}_{1}\right) \leq i_{\alpha, \beta}^{s}\left(\bar{B}_{2}\right)$, $i_{\alpha, \beta}^{s}\left(\bar{B}_{1}\right)+v_{\alpha, \beta}^{s}\left(\bar{B}_{1}\right) \leq i_{\alpha, \beta}^{s}\left(\bar{B}_{2}\right)+v_{\alpha, \beta}^{s}\left(\bar{B}_{2}\right) ;$ if $\bar{B}_{1}<\bar{B}_{2}$, then $i_{\alpha, \beta}^{s}\left(\bar{B}_{1}\right)+v_{\alpha, \beta}^{s}\left(\bar{B}_{1}\right) \leq i_{\alpha, \beta}^{s}\left(\bar{B}_{2}\right)$.

(ii) For any $\bar{B} \in L^{\infty}\left([0,1], \mathcal{L}_{s}\left(\mathbf{R}^{n}\right)\right)$,

$$
\begin{aligned}
& v_{\alpha, \beta}^{s}(\bar{B})=v_{\alpha, \beta}^{f}\left(\operatorname{diag}\left\{\bar{B}, I_{n}\right\}\right), \\
& i_{\alpha, \beta}^{s}(\bar{B})=i_{\alpha, \beta}^{f}\left(\operatorname{diag}\left\{\bar{B}, I_{n}\right\}\right) .
\end{aligned}
$$




\section{Competing interests}

The author declares that she has no competing interests.

\section{Author's contributions}

The author read and approved the final manuscript.

\section{Acknowledgements}

This work was supported by National Natural Science Foundation of China (Grant No.11171157) and the Jiangsu Planned Projects for Postdoctoral Research Funds. The author wants to express her sincere thanks to the referee for the valuable comments.

\section{Publisher's Note}

Springer Nature remains neutral with regard to jurisdictional claims in published maps and institutional affiliations.

Received: 6 October 2016 Accepted: 21 March 2017 Published online: 04 April 2017

\section{References}

1. Ekeland, I, Ghoussoub, N, Tehrani, H: Multiple solutions for a classical problem in the calculus of variations. J. Differ. Equ. 131, 229-243 (1996)

2. Dong, Y: Index Theory for Hamiltonian Systems and Multiple Solution Problems. Science Press, Beijing (2014)

3. Chen, Y, Dong, Y, Shan, Y: Existence of solutions for sub-linear or super-linear operator equations. Sci. China Math. 58, 1653-1664 (2015)

4. Hu, S, Lakshmikantham, V: PBVP for second order impulsive differential systems. Nonlinear Anal. 13, 75-85 (1989)

5. Li, Y, Zhou, Q: Periodic solutions to ordinary differential equations with impulses. Sci. China Ser. A 36, 778-790 (1993)

6. Dong, Y: Sublinear impulsive effects and solvability of boundary value problems for differential equations with impulses. J. Math. Anal. Appl. 264, 32-48 (2001)

7. Liu, B, Yu, J: Existence of solution for $m$-point boundary value problems of second-order differential systems with impulses. Appl. Math. Comput. 125, 155-175 (2002)

8. Zhang, F, Ma, Z, Yan, J: Boundary value problems for first order impulsive delay differential equations with a parameter. J. Math. Anal. Appl. 290, 213-223 (2004)

9. Qian, D, Li, X: Periodic solutions for ordinary differential equations with sublinear impulsive effects. J. Math. Anal. Appl. 303, 288-303 (2005)

10. Tian, Y, Ge, W: Applications of variational methods to boundary-value problem for impulsive differential equations. Proc. Edinb. Math. Soc. (2) 51 509-527 (2008)

11. Nieto, JJ, O'Regan, D: Variational approach to impulsive differential equations. Nonlinear Anal., Real World Appl. 10, 680-690 (2009)

12. Yuan, $X, X i a, Y, O$ 'Regan, D: Nonautonomous impulsive systems with unbounded nonlinear terms. Appl. Math Comput. 245, 391-403 (2014)

13. Sun, J, Chen, H, Nieto, JJ, Otero-Novoa, M: The multiplicity of solutions for perturbed second-order Hamiltonian systems with impulsive effects. Nonlinear Anal. 72, 4575-4586 (2010)

14. Zhou, J, Li, Y: Existence of solutions for a class of second order Hamiltonian systems with impulsive effects. Nonlinear Anal. TMA 72, 1594-1603 (2010)

15. Sun, J, Chen, H, Nieto, JJ: Infinitely many solutions for second-order Hamiltonian system with impulsive effects. Math. Comput. Model. 54, 544-555 (2011)

16. Qian, D, Chen, L, Sun, X: Periodic solutions of superlinear impulsive differential equations: a geometric approach. J. Differ. Equ. 258, 3088-3106 (2015)

17. Dong, Y: Index theory for linear self-adjoint operator equations and nontrivial solutions of asymptotically linea operator equations. Calc. Var. 38, 75-109 (2010)

18. Ekeland, I: Convexity Methods in Hamiltonian Mechanics. Springer, Berlin (1990)

19. Long, Y: Index Theory for Symplectic Paths with Applications. Progress in Math., vol. 207. Birkhäuser, Basel (2002)

\section{Submit your manuscript to a SpringerOpen ${ }^{\ominus}$ journal and benefit from:}

- Convenient online submission

- Rigorous peer review

- Immediate publication on acceptance

Open access: articles freely available online

- High visibility within the field

- Retaining the copyright to your article 